\title{
Eklem ve yüz anomalisi olan Larsen sendromlu bir vaka
}

\section{A case of Larsen sydrome with joint and fascial anomaly}

\author{
Didem ALIEFENDiOĞLU1a, Davut GÜL², Ayşegül ALPCAN, Emine D. MISIRLIOĞLU', Murad USLU³
}

${ }^{1}$ Kırıkkale Üniversitesi Tıp Fakültesi, Çocuk Sağlığı ve Hastalıkları Anabilim Dalı, Kırıkkale,

${ }^{2}$ Gülhane Askeri Tıp Akademisi, Tıbbi Genetik Anabilim Dalı, Ankara,

${ }^{3}$ Kırıkkale Üniversitesi Tıp Fakültesi, Ortopedi ve Travmatoloji Anabilim Dalı, Onkoloji Bilim Dalı, Kırıkkale, TÜRKiYE.

\begin{abstract}
ÖZET
Larsen sendromu doğan bebeklerin 100.000'de birinde görülen nadir bir genetik hastalıktır. Prenatal tanıdan ultrasonografinin önemi vardır. Yenidoğan döneminde tipik yassı yüz şekli, eklemlerde doğuştan dislokasyonlar, spinal deformite ile karakterizedir. Otozomal dominant formu ve daha ciddi klinik formu olan otozomal resesif tipi tanımlanmıştır. Bu çalışmada Larsen sendromlu bir vaka literatürdeki vakalar araştırılarak tartışılmıştır.
\end{abstract}

Anahtar kelimeler: Konjenital eklem dislokasyonları, Larsen sendromu, Prenatal tanı

\section{ABSTRACT}

Larsen syndrome is a rare genetic disorder, with an incidence of $1 / 100000$. Ultrasonography is important in prenatal diagnosis. Joint hypermobility, spinal deformity, congenital joint dislocations, distinctive facial features are characteristic findings in newborn. An autosomal dominant form and a more severe autosomal resesive form have been described. Larsen syndrome is discusessed with a review of literature.

Key words: congenital joint dislocations Larsen syndrome, prenatal diagnosis

\section{Giriş}

İlk 1950 yılında Larsen ve çalışma grubu tarafından 6 vaka ile tanımlanan Larsen sendromu oldukça nadir görülen bir hastalıktır [1]. İnsidansı yaklaşık 100.000 doğumda bir olarak tanımlanmıştır. Hastalığın otozomal dominant ve resesif görülen formu olmakla beraber sporodik vakalar da tanımlanmıştır [2]. Eklemlerde multiple bozukluklar, kardiyak anomaliler, baş boyun anomalileri eşlik edebilir [3]. Bu yazıda ortopedi bölümüne başvuran ve eşlik eden anomaliler nedeniyle kliniğimize refere edilen Larsen sendromlu bir olgu sunulmuştur.

\section{Olgu Sunumu}

24 yaşındaki annenin, ikinci gebeliğinden, ikinci yaşayan olarak, normal spontan vajinal yol ile term, 2800 gram, dış merkezde doğan bebek, postnatal 2. gününde el ve ayaklarındaki şekil bozukluğu nedeniyle başvurduğu ortopedi bölümü tarafından kliniğimize yönlendirildi. Antenatal izlem sırasında gebeliğin son aylarına kadar herhangi bir anormallikten bahsedilmeyen olgunun anne ve babası arasında ikinci derece akrabalık vardı ve diğer kardeşi tamamen sağlıklı idi. Hastanın anne ve babasına gebeliğin son aylarında bebeğin ayaklarında bozukluk olabileceği söylendiği öğrenildi.

Fizik incelemesinde, atipik yüz görünümü, burun kökü

Sorumlu Yazara: Dr. Didem ALiEFENDiOĞLU, Kırıkkale Üniversitesi Tıp Fakültesi Hastanesi, Çocuk Sağlığı ve Hastalıkları Anabilim Dalı, Kırıkkale, TURKEY 
basıklığı, hipertelorizm, inkomplet yarık damak, uzun el parmakları, bilateral kalça ve dizde dislokasyon ve dizlerde hiperekstansiyon mevcut idi (Resimler 1-4). (Hastanın ailesinden resimleri çekmek ve kullanmak için izin alınmıştır).

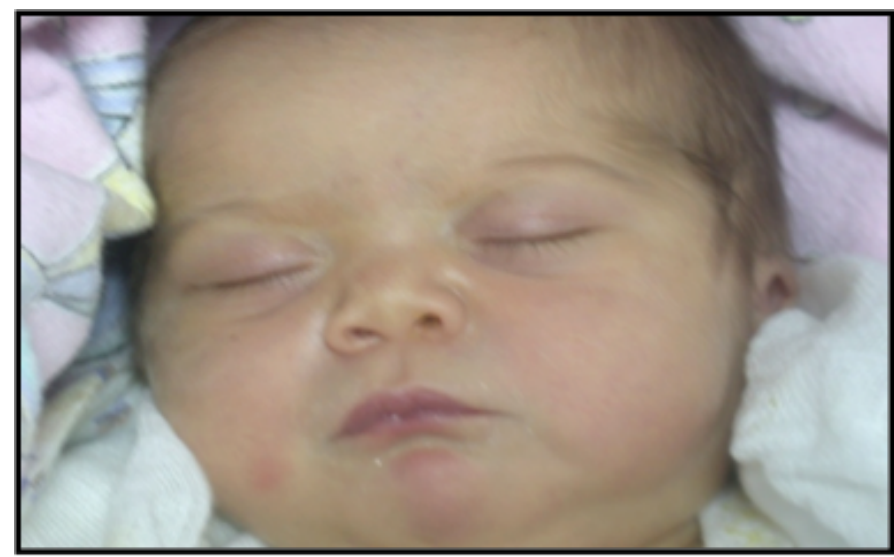

Resim1. Bebeğin yüz görünümü

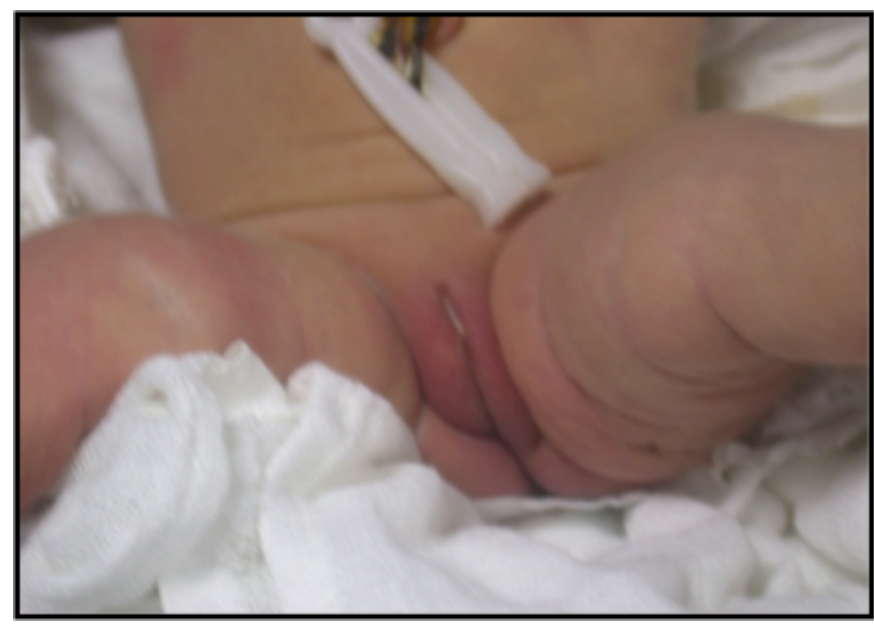

Resim 2. Bebeğin diz ekleminin görünümü

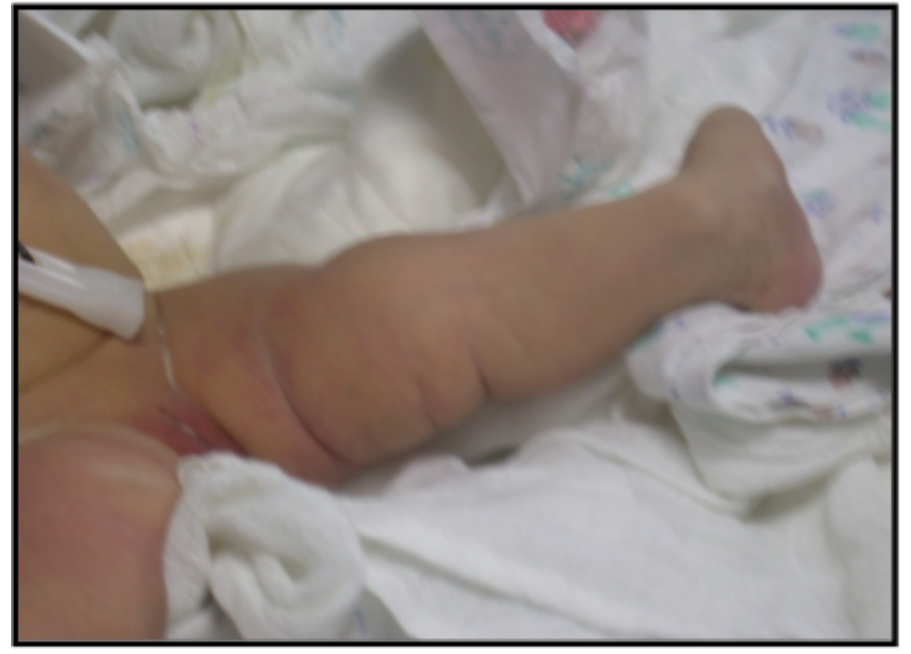

Resim 3. Bebeğin kalça ekleminin görünümü

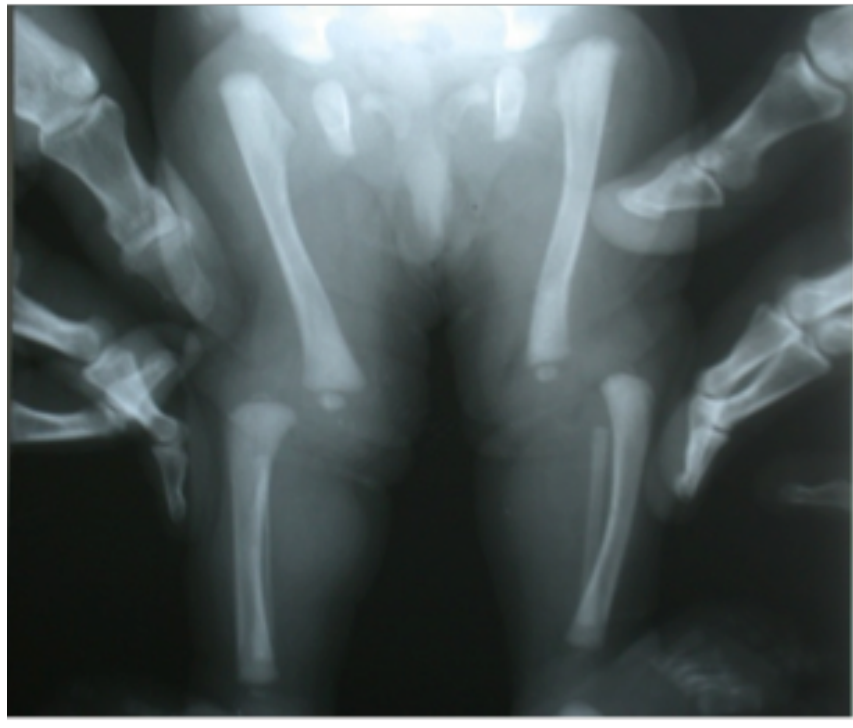

Resim 4. Alt ekstremite grafisi

Hastanın kan tetkiklerinde hemogram, AST, ALT, LDH, üre, kreatinin, sodyum, potasyum, kalsiyum, klor, fosfor ve tiroid fonksiyon testleri normal idi. Abdominal ve transfontanel ultrasonografi, ekokardiyografik inceleme, oküler değerlendirilme ve işitmesi normal olarak bulundu. Atipik yüz görünümü ve eklem bulguları nedeniyle Larsen sendromu düşünülen hastada genetik mutasyon tespit edilmedi. Hastamız alt ekstremitelerdeki dislokasyonlarına yönelik olarak ortopedi, çocuk nöroloji, plastik cerrahi ve fizik tedavi kliniği tarafından izlenmektedir.

\section{Tartışma}

Larsen sendromu kollajen doku yapımındaki bozukluk nedeniyle olan, oldukça nadir görülen bir hastalıktır. Sporodik vakalar olmakla beraber otozomal dominat ve resesif geçiş de bildirilmiştir [4,5]. Hastamızda akraba olan anne babanın ikinci çocuğuydu. Aile öyküsü sorgulandığında benzer eklem bozukluğu olan, atipik yüz görünümü olan birey olmadığı öğrenildi.

Larsen, 1950 yılında 6 hastada büyük eklemlerde multiple konjenital anomali ve yüz anomalisi tanımlamıştır. En çarpıcı bulgu olarak, basık yüz görünümü, eklem dislokasyonu ve ayaklarda ekinavarus deformitesi olarak tanımlamıştır [1]. Bazen hidrosefali, hipertelorizm, burun kökü basıklığı, geniş alın,yarık damak, el parmak anomalileri, vertebra anomalisi, pelvik böbrek, tek umbilikal arter, üst ekstremitelerde kısalık, karpal kemiklerde fazlalık, klinodaktili, parmak kemiklerinde uzunluk ve silindirik oluşum eşlik edebilir. Hastalara genellikle eklem problemlerinden dolayı agresif ortopedik yaklaşım gerekmektedir [4-6].

Hastamızda atipik yüz görünümü, burun kökü basıklığı, hipertelorizm, inkomplet yarık damak, uzun el parmakları, bilateral kalça ve dizde dislokasyon ve dizlerde hiperekstansiyon mevcut idi.

Larsen sendromuna eşlik eden işitme kayıplarından bahsedilmiştir [7]. Hastalarda eşlik eden trakeomalazi ve bronkomalazi ciddi solunum sıkıntısına neden olur [3]. 
Hastalarıngenetikincelemesi sonucunda kollagenyapımındaki genlerde mutasyonlar tespit edilmiştir. Literatürde parsiyel trizomi $1 q$ ve monozomi $6 p$ tespit edilmiş vakalar bildirilmiştir [8]. Bizim hastamızın genetik analizinde genetik anomali tespit edilemedi.

Konjenital diz dislokasyonu farklı formlarda ortaya çıkabilir. Basit hiperekstansiyon şeklinde, tibianın femurdan sublokasyonu şeklinde veya tibia ve femurda tam dislokasyon şeklinde olabilir. Genelde \%60 tek taraflı görülmektedir. Tendonlarda fibrozis ve kısalma sonucu diğer ortopedik problemlerde oluşabilir [8]. Hastamızda bilateral dislokasyon mevcut idi.

Hastaların ortopedik problemlerin tedavisi oldukça zordur. Agresif yaklaşım gereklidir. Bu hastalar yaşıtlarına göre geç yürürler. İleri dönemlerde büyük eklemlerde osteoartrit görülebilir [5,9].

İleri yaşa kadar gelmiş Larsen sendromlu kızlara gebelik öncesi genetik danışmalık verilmelidir. Hastalığın klinik bulgularının transvajinal ultrasonografi ile 15. gebelik haftasında tespit edilmesi mümkündür. Vakamızda gebeliğin son aylarında eklem anomalisi tespit edilmişti. Yüz anomalisinden bahsedilmemişti. Gebelikteki taramalarda prenatal ultrasonografi çok önemlidir. Fetusun yüzü mutlaka ayrıntılı değerlendirilmelidir. Eklem dislokasyonları yönünden dikkatli olunmalıdır. Eğer anomali tespit edilirse eşlik edebilecek kardiyak defektler açısından mutlaka fetal ekokardiyografi yapılmalıdır $[10,11]$.

Larsen sendromunun nadir de olsa ölümcül formları bildirilmiştir. Bu formların daha çok otozomal resesif geçiş ile olduğu düşünülmektedir. Bu hasta grubunda eklem anomalileri çok ciddi seyredip genelde ölüm akciğer hipoplazisi nedeniyle olmaktadır [12,13].

Sunulan bu vakada eşlik eden büyük eklem ve yüz anomalisi nedeniyle Larsen sendromu düşünülmüştür. Hastamızda, literatürlerde belirtilen eşlik edebilecek kardiyak anomaliler $[14,15]$ açısından yapılan kardiyolojik inceleme de biküspit aorta, mitral kapak prolapsusu, mitral yetmezlik, atrial septak defekt gibi kardiyak anomaliler saptanmadı. Hastada atipik yüz görünümü ve inkomplet yarık damak vardı. Hasta bu sebeple plastik cerrahi tarafından takibe alındı. Bacaklarındaki major eklem deformiteleri için ise fizik tedavi ortopedi ve çocuk nöroloji tarafında tedavi ve rehabilitasyon takibine alındı.

\section{Çıkar çatışması ve Finansman Beyanı}

Bu çalışmada çıkar çatışması ve finansman destek alındığı beyan edilmemiştir.

\section{Kaynaklar}

1. Larsen LJ, Schottstaedt ER,Bost FC. Multiple congenital dislocations associated with characteristic facial abnormality. J Pediatr 10950; 37: 574-81.

2. Bicknell LS, Farrington-Rock C, Shafeghati Y, et al. A molecular and clinical study of Larsen syndrome caused by mutations in FLNB. J Med Genet 2007; 44: 89-98.

3. Stevenson GW, Hall SC, Palmieri J. Anesthetic considerations for patients with Larsen's syndrome.. Anesthesiology 1991; 75: 142-4.

4. Kiel EA, Frias JL, Victorica BE. Cardiovascular manifestations in the Larsen syndrome. Pediatrics 1983; 71: 942-6.

5. Al-Kaissi A, Ammar C, Ben Ghachem MB, Hammou A, Chehida FB. Facial features and skeletal abnormalities in Larsen syndrome--a study of three generations of a Tunisian family. Swiss Med Wkly 2003; 133: 625-8.

6. Al Kaissi A, Altenhuber J, Grill F, Klaushofer K. Significant traumatic atrophy of the spinal cord in connection with severe cervical vertebral body hypoplasia in a boy with Larsen syndrome: a case report and review of the literature cases J 2009; 17: 6729.

7. Stanley CS, Thelin JW, Miles JH. Mixed hearing loss in Larsen syndrome. Clin Genet 1988; 33: 395-8.

8. Pierquin G, Van Regemorter N, Hayez-Delatte et al. Two unrelated children with partial trisomy $1 \mathrm{q}$ and monosomy $6 p$, presenting with the phenotype of the Larsen syndrome. Hum Genet 1991; 87: 587-91.

9. Babat LB, Ehrlich MG. A paradigm for the age-related treatment of knee dislocations in Larsen's syndrome. J Pediatr Orthop 2000; 20: 396-401.

10. Benacerraf BR. Ultrasound of fetal syndromes. New York, Churchill Livingstone, 1998; 150-151.

11. Tongsong T, Wanapirak C, Pongsatha S, Sudasana J. Prenatal sonographic diagnosis of Larsen syndrome. J Ultrasound Med 2000; 19: 419-21.

12. Mostello D, Hoechstetter L, Bendo RW, et al. Prenatal diagnosis of recurrent Larsen syndrome further definition a lethal variant. Prenat Diagn 1991; 11:215-25.

13. Le Marec B, Chapuis M, Treguier C, Odent S, Bracq H. A case of Larsen syndrome with severe cervical malformations. Genet Couns 1994; 5: 179-81.

14. Liang $C D$, Hang CL. Elongation of the aorta and multiple cardiovascular abnormalities associated with Larsen syndrome. Pediatr Cardiol. 2001; 22: 245-6.

15. Stevenson GW, Hall SC, Palmieri J. Anesthetic considerations for patients with Larsen's syndrome. Anesthesiology 1991; 75: 142-4. 